\title{
COVID-19 Infection in Sickle Cell Patients in a Developing Country: A Case Series
}

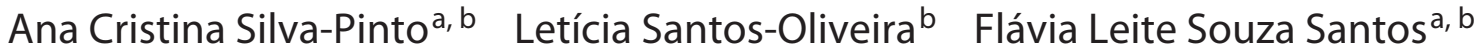 \\ Simone Kashima Haddad ${ }^{a}$ Gil Cunha De Santis ${ }^{a, b}$ Rodrigo do Tocantins Calado a,b \\ aRegional Blood Center, Ribeirão Preto School of Medicine, University of São Paulo, São Paulo, Brazil; bepartment of \\ Medical Imaging, Hematology, and Oncology, Ribeirão Preto School of Medicine, University of São Paulo, São Paulo, Brazil
}

\section{Keywords}

Sickle cell disease $\cdot$ ABO blood group - SARS-CoV-2 .

COVID-19

\section{Abstract}

Sickle cell disease is characterized by vaso-occlusive phenomena and haemolytic anaemia. There is a significant concern that the overlap of COVID-19 lung disease with acute chest syndrome that occurs in sickle cell patients may result in serious complications. Case reports of sickle cell patients with COVID-19 have been published. Here, we present a case series of COVID-19 infection in sickle cell patients in a developing country (Brazil). Only 10 patients tested positive so far for SARS-CoV-2 of 600 patients followed at our institution, of which 8 needed hospitalization (one in the intensive care unit), with no deaths. Even in a middle-income country, COVID-19 was reported to be relatively mild in sickle cell patients. In relation to risk factors, blood type $\mathrm{O}$ seems to confer some protection against developing severe COVID-19, a finding that could guide clinicians to adopt more clinical surveillance for patients with non-O blood type in sickle cell patients.

(c) 2021 S. Karger AG, Basel

\section{Introduction}

Sickle cell disease (SCD) is a hereditary group of disorders characterized by the presence of haemoglobin S, either in homozygosity or in composed heterozygosity with another $\beta$-globin mutation (S $\beta$ thalassaemia, SC, and SD haemoglobinopathies). Together, SCD is characterized by vaso-occlusive phenomena and haemolytic anaemia $[1,2]$.

One of the main causes of mortality in SCD patients is acute chest syndrome (ACS). ACS can result from sickling in the small blood vessels, infarction or pulmonary embolism, or viral or bacterial pneumonia. The treatment of ACS is challenging and requires surveillance by the medical team, hospitalization, often in the intensive care unit (ICU), ventilatory support, transfusion, and antibiotic therapy $[3,4]$.

COVID-19 is a mild viral infection in $80 \%$ of cases. Nevertheless, $20 \%$ of patients develop interstitial pneumonia, acute respiratory syndrome, sepsis, and septic shock [5]. There is a significant concern that the overlap of COVID-19 lung disease with the ACS might result in severe outcomes in this population. In addition, both
Correspondence to:

Ana Cristina Silva-Pinto, acristina@ hemocentro.fmrp.usp.br 
Table 1. Clinical characteristics of the patients included in the study

\begin{tabular}{|c|c|c|c|c|c|c|c|c|c|}
\hline Patients & Age & Sex & Genotype & Previous treatments & Previous complications & $\begin{array}{l}\text { Complication during } \\
\text { hospitalization }\end{array}$ & $\begin{array}{l}\text { Blood } \\
\text { group }\end{array}$ & BMI & $\begin{array}{l}\text { Length of } \\
\text { stay, days }\end{array}$ \\
\hline 1 & 30 & $\mathrm{~F}$ & SS & Clinical trial & ACS & VOC & $A$ & 22.4 & 5 \\
\hline 3 & 30 & $\mathrm{~F}$ & SBETAO & $\mathrm{HU}$ & ACS & ACS & $A$ & 24.8 & 10 \\
\hline 4 & 33 & $\mathrm{~F}$ & SC & None & Myocarditis & ACS & $A$ & 22.4 & 4 \\
\hline 5 & 45 & $M$ & SS & Chronic transfusion & Stroke + leg ulcers & VOC & $A$ & 25.6 & 22 \\
\hline 8 & 36 & $\mathrm{~F}$ & SS & HU & $A C S+V O C$ & ACS & $\mathrm{O}$ & 23.32 & 11 \\
\hline 9 & 31 & $\mathrm{~F}$ & SS & $\mathrm{HU}$ & VOC & - & $A$ & 22.93 & - \\
\hline 10 & 8 & $\mathrm{~F}$ & SS & $\mathrm{HU}$ & ACS & - & B & 16 & - \\
\hline
\end{tabular}

M, male; F, female; SS, sickle cell anaemia; SBETA0, S $\beta$ thalassaemia; SC, haemoglobinopathy SC; HU, hydroxyurea; ACS, acute chest syndrome; VOC, vaso-occlusive crisis; BMI, body mass index.

COVID-19 and SCD favour the occurrence of thromboembolic events, so the association of these 2 diseases could greatly increase the risk of occurrence of complication [6]. In Europe and in the USA, case reports of SCD patients with COVID-19 have already been published, and the relatively good clinical outcome was somehow surprising, considering the susceptibility of SCD patients to infections and vaso-occlusion complications [6-8].

In a case series of 4 sickle cell patients treated in the USA, the authors showed a mild clinical course in most of them, despite having a previous history of ACS in 3 patients and pulmonary embolism in the other one, with no deaths [6]. In another case series, from a UK tertiary hospital, 10 patients (7 females) with SS genotype and ages between 25 and 54, the authors reported only 1 death. Five patients had mild COVID-19 infection and were not hospitalized and 4 recovered after a short period of hospitalization [7]. The French national consortium published the clinical outcome of 83 SCD patients with COVID-19. The median age was 33.5 years for the adult population and 12 for paediatric patients (0.3-17); $58 \%$ had a history of ACS and $20 \%$ were admitted to ICU. Only 2 patients died, both with the SC genotype. Patients aged above 45 years were at higher risk of admission to ICU. Hence, the authors suggested that COVID-19 was mild in most of the patients, especially those younger than 45 years [8]. Brazil is being greatly affected by the pandemic. Over 17 million people across the country were infected so far, and $>480,000$ people died of COVID-19. According to our Ministry of Health, there are between 30 and 70,000 sickle cell patients in Brazil [9], and the clinical outcome of those patients with COVID-19 is largely unknown; however, we believe that this report can contribute to show the outcomes in patients with SCD and COVID-19 in this country.

\section{Case Series}

This is an observational retrospective study of all the SCD patients diagnosed with COVID-19 followed at our institution. The study was approved by the institutional ethics committee, which waived the need for the informed consent from the patients. We report here 10 ( $1.7 \%$ of 600 patients followed at our institution) SCD patients with COVID-19 (confirmed by RT-PCR; all cases caused by the original variant). Their clinical characteristics and outcomes are described in Table 1 . Nine patients were adults, and one was an 8-year-old child with the SS genotype. Eight adult patients were admitted to the hospital, of which 1 patient $(n=8)$ was admitted to ICU and underwent mechanical ventilation support. The overall mean length of hospitalization was 11.4 days (range 4-22 days). The causes of hospitalization were vaso-occlusive phenomena in 2 patients and ACS in 6 patients. We performed descriptive statistics for general data and Fisher's exact test to analyse categorical variables.

The ABO blood group types of the patients were 6 type A, 1 type $\mathrm{AB}, 1$ type $\mathrm{B}$, and 2 type $\mathrm{O}$. The control subjects were the SCD population followed at our institution who had their blood typing performed $(n=204)$. Blood groups $\mathrm{A}, \mathrm{AB}$, and B were overrepresented $(80 \%)$ in the COVID-19 group related to the control group (56\%), whereas blood group $\mathrm{O}$ was less represented: $20 \%$ in the COVID-19 group versus $44 \%$ in the sickle cell population. Although this result did not reach statistical significance, the prevalence of the O blood group among the COVID-19 patients was less than half of the control group. 


\section{Discussion}

Interestingly, as observed in this case series and in other published studies [6-8], the low number of SCD patients needing to be hospitalized for COVID-19 was somewhat surprising and raises the hypothesis that SCD patients are perhaps not as vulnerable to COVID-19 as has been supposed at the beginning of the pandemic. Some of the recognized risk factors for COVID-19 infection, such as obesity, diabetes, and hypertension, are very rare in SCD patients. SCD patients tend to be younger than the general population, with a lower percentage of older individuals, who are known to be more vulnerable to COVID-19. The median age of our 9 adult patients was 31 years, with no patients above 45 years of age, a risk factor for COVID-19 complication in sickle cell disease [8]. Besides, none of our patients had obesity, type II diabetes, or hypertension. An additional protective factor could be the chronic inflammatory status present in SCD, which may play a role in reducing the vulnerability to the virus and even the intensity of the inflammatory storm that frequently occurs in COVID-19, as suggested by others [8]. Nevertheless, although mortality in SCD patients with COVID-19 is less than had been expected, it is still high compared to the healthy population when corrected for age and comorbidities [10].

It has been previously proposed that group $\mathrm{O}$ confers a relative protection against SARS-CoV-1 infection [11]. In that study, blood group $O$ healthcare professionals were less susceptible to become infected than nongroup $\mathrm{O}$ individuals. Zhao and colleagues [12] were the first to show that the proportion of blood group A patients infected with SARS-CoV-2 was higher than that observed in healthy subjects ( $39.3 \%$ vs. $32.3 \%)$. Additional studies confirmed the association between blood group A and COVID-19 infection [13-16]. One possible explanation is the higher plasma levels of von Willebrand factor and the higher risk of thrombosis in comparison with group O subjects [17-19]. Additionally, it is possible that anti-A antibodies (present in blood type $\mathrm{O}$ individuals) may interfere with SARSCoV-2 and target cell integration, as previously demonstrated for SARS-CoV-1 [20]. These hypotheses need to be addressed in further studies. Here, we suggest that there could be an association between $\mathrm{ABO}$ blood group and COVID-19 in patients with SCD.

We acknowledge some limitations of our study. First, the number of patients is relatively small; however, we included all SCD patients diagnosed for COVID-19 at our institution, so far. Second, we do not provide mecha- nistic evidence for this association and the reason(s) why non-O blood group SCD patients seem to be more vulnerable to develop severe COVID-19.

In conclusion, we have shown that SCD patients with COVID-19 have a relatively favourable outcome, even in a middle-income country. Another finding is that blood type $\mathrm{O}$ seems to confer some protection against developing COVID-19, a finding that could, possibly, guide clinicians to adopt a closer clinical surveillance for patients with non-O blood type in sickle cell patients.

\section{Acknowledgment}

We thank Nathália Cristine André for her assistance.

\section{Statement of Ethics}

This research was conducted ethically in accordance with the Declaration of Helsinki. The study was approved by our local institutional ethics committee, which dismissed the need for the written informed consent from the patients. Ethical approval date: September 15, 2020 (Process No. 4.277.529).

\section{Conflict of Interest Statement}

The authors declare no conflicts of interest.

\section{Funding Sources}

This study received funding from FAPESP (2020/05367-3).

\section{Author Contributions}

All authors contributed to the study conception and design. Material preparation, data collection, and analysis were performed by Ana Cristina Silva-Pinto, Letícia Santos-Oliveira, Flávia Leite Souza Santos, and Gil Cunha De Santis. The first draft of the manuscript was written by Ana Cristina Silva-Pinto, and all authors commented on previous versions of the manuscript. All authors read and approved the final manuscript.

\footnotetext{
References

1 Bunn HF. Pathogenesis and treatment of sickle cell disease. N Engl J Med. 1997;337:762.

2 Rees DC, Williams TN, Gladwin MT. Sicklecell disease. Lancet. 2010;376:2018.

3 Gladwin MT, Vichinsky E. Pulmonary complications of sickle cell disease. N Engl J Med. 2008;359:2254.
} 
4 Vichinsky EP, Neumayr LD, Earles AN, Williams R, Lennette ET, Dean D, et al. Causes and outcomes of the acute chest syndrome in sickle cell disease. National Acute Chest Syndrome Study Group. N Engl J Med. 2000; 342(25):1855-65.

5 Pascarella G, Strumia A, Piliego C, Bruno F, Del Buono R, Costa F, et al. COVID-19 diagnosis and management: a comprehensive review. J Intern Med. 2020 Aug;288(2):192206.

6 Hussain FA, Njoku FU, Saraf SL, Molokie RE, Gordeuk VR, Han J. COVID-19 infection in patients with sickle cell disease. Br J Haematol. 2020 Jun;189(5):851-2.

7 Chakravorty S, Padmore-Payne G, Ike F, Tshibangu V, Graham C, Rees D, et al. COVID-19 in patients with sickle cell disease - a case series from a UK Tertiary Hospital. Haematologica. 2020 Nov 1;105(11):2691-3.

8 Arlet JB, de Luna G, Khimoud D, Odièvre $\mathrm{MH}$, de Montalembert M, Joseph L, et al. Prognosis of patients with sickle cell disease and COVID-19: a French experience. Lancet Haematol. 2020 Sep;7(9):e632-4. Erratum in: Lancet Haematol. 2020 Sep;7(9):e635.

9 Cançado RD, Jesus JA. A doença falciforme no Brasil. Rev Bras Hematol Hemoter. 2007; 29(3):204-6.
10 Telfer P, De la Fuente J, Sohal M, Brown R, Eleftheriou P, Roy N, et al. Real-time national survey of COVID-19 in hemoglobinopathy and rare inherited anemia patients. Haematologica. 2020 Nov 1;105(11):2651-4.

11 Cheng Y, Cheng Y, Cheng G, Chui CH, Lau FY, Chan PK, et al. ABO blood group and susceptibility to severe acute respiratory syndrome. JAMA. 2005 Mar 23;293(12):1450-1. Erratum in: JAMA. 2005 Aug 17;294(7):794. Cheng, Yufeng [corrected to Cheng, Yunfeng].

12 Zhao J, Yang Y, Huang H, Li D, Gu D, Lu X, et al. Relationship between the ABO blood group and the coronavirus disease 2019 (COVID-19) susceptibility. Clin Infect Dis. 2021 Jul 15;73(2):328-31.

13 Severe Covid-19 GWAS Group; Ellinghaus D, Ellinghaus D, Degenhardt F, Bujanda L, Buti $\mathrm{M}$, Albillos A, et al. Genomewide association study of severe Covid-19 with respiratory failure. N Engl J Med. 2020 Oct 15;383(16):152234.

14 Li J, Wang X, Chen J, Cai Y, Deng A, Yang M. Association between $\mathrm{ABO}$ blood groups and risk of SARS-CoV-2 pneumonia. Br J Haematol. 2020 Jul;190(1):24-7.

15 Wu Y, Feng Z, Li P, Yu Q. Relationship between $\mathrm{ABO}$ blood group distribution and clinical characteristics in patients with COVID-19. Clin Chim Acta. 2020 Jun 17;509:2203.
16 Garibaldi PMM, Oliveira LC, da Fonseca BA, Martins MA, Miranda CH, Almado CEL, et al. Histo-blood group A is a risk factor for severe COVID-19. Transfus Med. Epub 2021 Jun 3.

17 Franchini M, Capra F, Targher G, Montagnana M, Lippi G. Relationship between ABO blood group and von Willebrand factor levels: from biology to clinical implications. Thromb J. 2007 Sep 25;5:14

18 De Santis GC, Prata KL, Rodrigues RB, Sankarankutty AK, de Castro e Silva O, Covas DT. Blood group $\mathrm{O}$ patients require more blood transfusion in orthotopic liver transplantation. Transfus Apher Sci. 2014 Apr; 50(2):312-3.

19 Vasan SK, Rostgaard K, Majeed A, Ullum H, Titlestad KE, Pedersen OB, et al. ABO blood group and risk of thromboembolic and arterial disease: a study of 1.5 million blood donors. Circulation. 2016 Mar 3;133:1449-57.

20 Guillon P, Clément M, Sébille V, Rivain JG, Chou CF, Ruvoën-Clouet N, et al. Inhibition of the interaction between the SARS-CoV spike protein and its cellular receptor by antihisto-blood group antibodies. Glycobiology. 2008 Dec;18(12):1085-93. 